\title{
Enculturation of the Russian Youth in the Modern Digital Educational Environment
}

\author{
Svetlana S. Zubareva* \\ Don State Technical University, 344000 Rostov-on-Don, Russia
}

\begin{abstract}
On the cusp of the $20^{\text {th }}$ and $21^{\text {st }}$ centuries, during the period of progressing globalization processes, all social institutions, including science and education, saw major changes. On the one hand, the transitivity of the modern society has influenced the changes in the system of social values and attitude to the information, a priori knowledge and university as the place of tits production and accumulation. On the other hand, the penetration of digital culture, containing new values and meaning of education has had a massive effect on the formation of certain patterns of subject-subject relations in the educational process. The purpose of this study was to explore the opportunities and risks associated with education of Russian students and to analyze social and axiological aspects of this process. In the course of our study we analyzed the differences between generations that are subjects of the educational process and presented key sociocultural characteristics of the student youth determining their approach to studies. The conducted analysis shows that as digital culture bearers Russian students adapt quickly to ongoing social and technological transformations/ as well as perceive and share the values of the academic community and future profession.
\end{abstract}

\section{Introduction}

The sociocultural transformation that took place in the Russian Federation in the late $20^{\text {th }}$ early $21^{\text {st }}$ centuries as a result of global reformation and anthropologic revolution, as well as the establishment of postindustrial (information-oriented) society caused the occurrence of a new generation of people, called "digital generation" [1]. Under the conditions of the information-oriented society the role of knowledge as a sign of professionalism and the position of higher educational institutions as the center of its production and accumulation has changed dramatically. Research \& development are becoming the mainspring of the economic development - the basis of the knowledge industry, while human capital assets are the key intensive factor of the development in the postindustrial society. In the course of this sociocultural transformation, in 2017, the government of the Russian Federation approved the program "Digital Economy of the Russian Federation". The program aimed at the arrangement of system development and digitization of every area of life: economy, public administration, social sphere, and urban economy. In this regard a particular relevance is attached to the development of young skilled professionals — the future of digital economy, who are able to ensure global competitive ability and national security — in

\footnotetext{
*Corresponding author: zubareva.ss@yandex.ru
} 
conditions of digital educational environment. During their studies the students not only acquire certain educational competences through acquisition of academic knowledge and solution of professional tasks, but they also become a part of the academic community, where the subject-subject relationships between the representatives of different generations are of special importance. Due to this, we face the challenge to identify specific aspects of enculturation of modern students during their studies, giving special consideration to the relationships between the students and the teaching staff as representatives of different generations.

\section{The phenomenon of inculturation in the modern educational environment}

The study was conducted with the application of general scientific and philosophical methods of cognition. The principles of dialectics, including the principle of universal relation between phenomena, determinism and the principle of development, have a significant role in the methodological procedures of the study. When studying the process of changes in the value-based consciousness of a personality and cultural identity in the information-oriented society, the author applied the methods of social research, as well as the methods of statistical data processing and visual presentation of results as line graphs. The experimental study involved the representatives of different educational institutions in Rostov-on-Don, who belong to different generations. The study sample was 250 people. The study objects are 4 educational institutions of various levels, including 1 vocational education institution, 1 gymnasium, 2 higher educational institutions. The study subject is the analysis of social and axiological aspects of Russian students' education in the digital educational environment.

Enculturation of the Russian youth in the modern educational environment is largely related to the mastering of professional competences and practice-oriented education. However, this process involves the communication with the teaching staff, representing different scientific schools. A specific feature of intergenerational communication is the gap between the value orientations of different generations and determined by the crisis in the axiosphere of the Russian society, which is noted these days [2]. Each social and demographic group has its individual sociocultural experience of socialization in exceptional conditions. This determines their social and psychological peculiarities, including set of mind, mentality, values, value orientations, way of thinking, style of life, code of behavior, motivation, world view, forms of activity, norms, and interaction patterns.

Currently, several generations are interacting in the Russian digital educational environment, including "Soviet generation", "transitional generation", "post-Soviet generation" and new "digital generation" [3]. Within the framework of this study a special interest is given to the sociocultural analysis of the intergenerational continuity, especially the relationships between the Soviet and digital generations. Today, the Soviet generation is represented by the people of mature age, who were brought up in the era of socialism with a strong ideology component. They are predisposed toward sharing the experience of the conquest, acting as bearers of the structured traditions, relationships and moral standards. The experts note that the style of interaction typical of the teachers of Soviet generation is characterized by the absence of commitment to true understanding and the desire to be understood, focus on imitation, reactive communication, readiness to adapt to the interlocutor; herewith, they ignore the communication by itself with all of its problems that may arise, they largely focus on communication only on "business matters" and avoid informal socializing in extracurricular activities [4]. An important characteristic of senior generation representatives is their commitment to higher education and area of occupation, while the young generation representatives strive for multimodal education in various fields of science, in order to meet current requirements for a well-rounded professional. At the same time the representatives of this generation have computerphobia to a greater or lesser degree.

This significantly complicates their interaction with the modern youth. The digital 
generation was formed under the influence of information-communication, computer and digital technologies, determining the character of socialization of their representatives, specificity of their value orientations, network identity and sociocultural image. Following the trends of the information society, the educational system in Russia has changed a lot, for example, some new models and theories of education appear, including tutoring, involving the use of mobile devices to maintain contact with tutors through apps like Whatsapp or Facebook; joint online education; learning through play, group projects [5]. In the course of education, they interact with Internet technologies, advanced software, which let them create the Internet products of their own, acquire and digest large amounts of information in short time. A modern generation of students is distinguished by a high level of skills and abilities of effective information retrieval in the media space and pragmatic perception of such space [6]. Therefore, the virtual space provides opportunities for self-actualization through simulacralization and participation in the social processes similar to those happening in the physical world.

\section{The dynamics of modern youth value orientations}

According to the empiric study aimed at determining the trends of intergenerational continuity in the society and identifying the susceptibility of modern Russian youth to the translated values of the Russian culture, the following social and cultural characteristics have been revealed. The choice of the field of studies and direction of education was determined by family traditions in $13.8 \%$; however, in $76.4 \%$ of cases this choice was determined by personal preferences; the R\&D activities within the selected area is attractive for the young generation, $20.3 \%$ of young people are members of R\&D and design and experimental groups, and $13 \%$ presents the results of their work at scientific conferences and have publications; most young people (48\%) share the values of scientific cosmopolitism and $26.4 \%$ communicate with scientists from other countries; the dynamics of value orientations is also characterized by the fact that when conducting scientific activities such qualities as a width of views, independence and optimism are of paramount importance for the representatives of the digital generation, which differ them from the paradigm of young scientists in the Soviet period.

In present-day Russia professional self-fulfillment is possible in different sectors of economy. In this regard, there is a keen interest to the factors determining the choice at the moment of decision making.

\section{Dynamics of the value orientations when making an occupational choice}

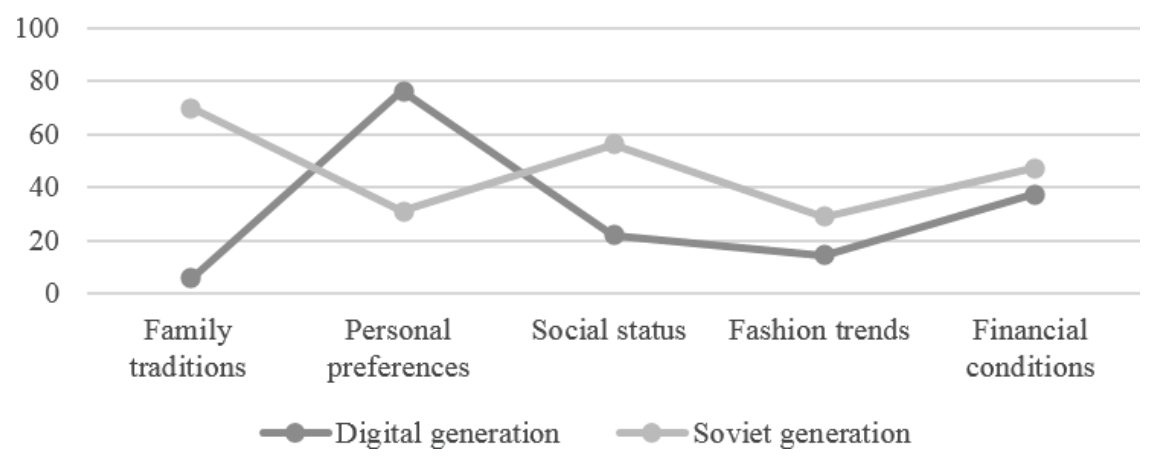

Fig. 1. Dynamics of the value orientations when making an occupational choice 
According to the data presented in Figure 1, these days personal preferences are the most important (76.4\%). The least important factors are family traditions and fashion trends, 5.7\% and $14.2 \%$, respectively. Therefore, a modern young person is absolutely free to plan his/her future and place in the society. Such person is ready to make decisions without drawing on the experience of previous generations or being influenced the fashion on some occupations. This largely differ him/her from previous generations, especially from the Soviet generation, who tended to continue family professional dynasties, maintaining a certain social status, which they acquire together with mastering the professions.

In the course of study, we also considered the value orientations typical of young scientists in the Soviet Union and of the modern generation of researchers.

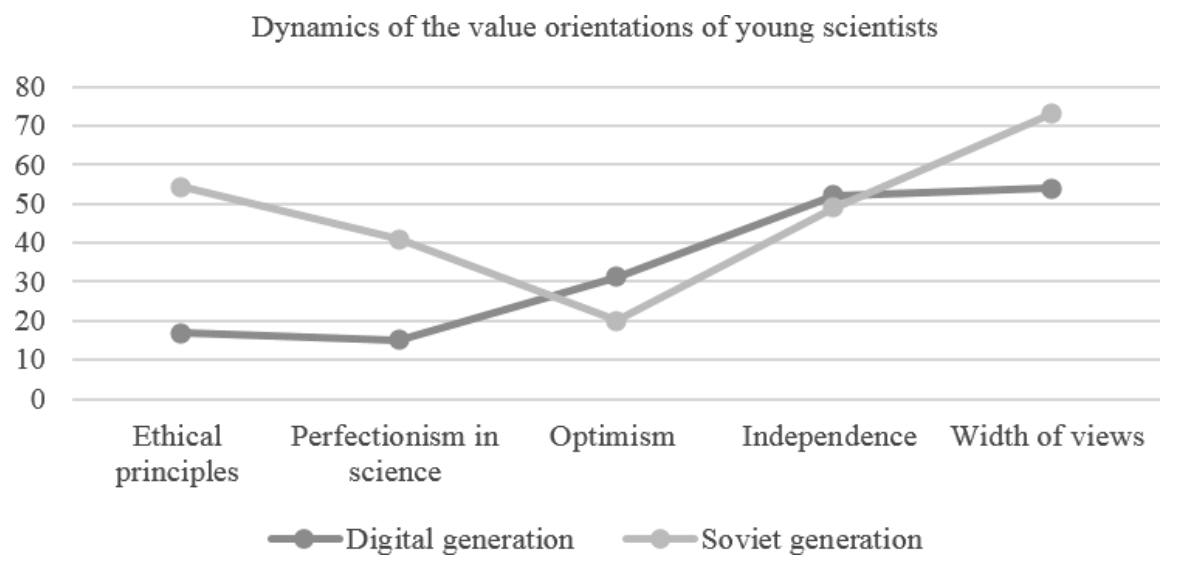

Fig. 2. Dynamics of the value orientations of young scientists

According to the data presented in Figure 2, both the Soviet generation of scientists and modern young scientific community adheres to the principles of independence and wide world view; nonetheless, cardinal differences in the value orientations are noted in the observance of the principles ethics and responsibility in scientific pursuits.

\section{Social and cultural characteristics of digital generation}

Having listed the value orientations determining the process of youth enculturation into the digital educational environment, let us consider sociocultural peculiarities of the Russian studentship. A key peculiarity is the transformation in the mindset of the digital generation, i.e. occurrence of the clip way of thinking, which is one of the factors of anthropologic revolution. One of sociocultural markers of the "digital" generation is the use of various social media in the educational activity, including educational portals, additional virtual tools and analytical programs. In addition to educational gaming services, such platforms involve communication and mutually-beneficial exchange of data and proposals between school and university students, employers, universities, investors and organizers of educational and scientific events [7]. A distinctive feature of the "digital" generation is that the after socialization in conditions of total globalization, European integration and spread of the Internet, the representatives of this generation do not have any mental barriers when communicating with the representatives of other cultures. Therefore, considering that the sociocultural image of modern youth was formed within the culture of virtual, digital, wired world, it reflects the transformation trends in the personality's self-perception, which formed on the basis of perception of electronic self-image. 


\section{Conclusions}

Summarizing the above, we can draw the following conclusion. The enculturation of the Russian youth in the modern digital educational space we accompanied not only by deep involvement into the practice-oriented environment, aimed at inclusion into the professional culture but also by interaction with the representatives of different generations within the subject-subject relations during education. When identifying the trends in the intergenerational continuity in the Russian science and determining the susceptibility of the modern Russian youth to the values of the academic community and professional activity, we found the following: the choice of the field of studies and direction of education is determined by both family traditions and personal preferences; the young generation finds attractive the R\&D activities within the chosen direction of education; they share the values of scientific cosmopolitism and interact with colleagues from other countries; the paramount values of the digital generation are a width of views, independence and optimism, which differ them from the paradigm typical of the generation of young scientists in the Soviet period. At the same time the notes differences in the approach to the solution of professional tasks arising between various generations do not exclude the opportunity of their selffulfillment and self-actualization. Thus, we can say that the sociocultural image of the digital generation includes a specific way of thinking, high literacy and the experience in communication with new information and computer technologies, as well as a nonstandard approach to the solution of production tasks. They are bearers of a unique system of values that formed in conditions of the convergence of the Russian and digital cultures of the global space, which translates into their quick response, ability for multitasking and an innovative approach to the classical education, which is now transforming to adapt the needs of a new generation and in line with the digital innovative economy. The conducted analysis shows that as bearers of the digital culture, Russian students quickly adapt to the ongoing social and technological transformations, as well as perceive and share the values of the academic community and future profession.

\section{References}

1. D. Tappscott, Growing up digital: The rise of the net generation (McGraw Hill, New York, 2011)

2. V. Kotlyarova, Humanitarian and social sciences. II, 80-85 (2011)

3. V. Pishchik, Russian Psychological Journal. I, 215-236 (2018)

4. V. Pishchik, A. Gavrilova, N. Sivrikova, Russian Psychological Journal. I, 245-264. (2016)

5. M. Savin-Baden, D. Burden, Postdigital Science and Education I, 123 (2018)

6. N. Sivrikova, V. Zherebkina, M. Postnikova, Russian Psychological Journal, I, 70-87. (2017)

7. M. Ereshchenko, E. Zubareva, S. Zubareva, INTED2019 Proceedings, I, 5895-5899 (2019) 